\title{
EFEITO DO RALEIO DE FRUTOS SOBRE O DANO DE Bonagota cranaodes (MEYRICK, 1937) (LEPIDOPTERA: TORTRICIDAE) EM CULTIVARES DE MACIEIRA
}

\author{
EFFECT OF FRUIT THINNING ON Bonagota cranaodes (MEYRICK, 1937) \\ (LEPIDOPTERA: TORTRICIDAE) DAMAGE ON APPLE CULTIVARS
}

\author{
Marcos Botton $^{1}$ Octávio Nakano ${ }^{2}$ Adalécio Kovaleski ${ }^{3}$
}

\begin{abstract}
$O$ efeito do rateio de frutos de maça sobre o dano RESUMO provocado pela tagarta-enroladeira Bonagota cranaodes (Meyrick, 1937) (Lepidoptera: Tortricidae) foi avaliado em pomares comercias das cultivares Gala e Fuji, em Vacaria, RS. $\mathrm{Na}$ colheita, através de amostragem, foi registrada a porcentagem de maçãs danificadas, quando produzidas deforma isolada, e daquelas provenientes de cachopas florais formadas por dois, três e quatro frutos. Observou-se uma correlação positiva entre o número de frutos por cacho floral $e$ a porcentagem de maçãs danificadas pelo inseto. Devido ao fato de que a cultivar Gala é mais precoce (colheita em fevereiro), o dano médio observado foi significativamente inferior ao da Fuji, cuja colheita é mais tardia (abril). Frutos produzidos de forma isolada nos ramos florais foram significativamente menos danificados pela praga, indicando, através do rateio de frutos, ser possível reduzir os prejuízos causados pela lagartaenroladeira nos pomares de macieira.
\end{abstract}

Palavras-chave: Insecto, lagarta-enroladeira da maçã, dano em frutos, controle cultural.

\section{SUMMARY}

The effect of fruit thinning on apple leafroller Bonagota cranaodes (Meyrick, 1937) (Lepidoptera: Tortricidae) damage was evaluated in commercial orchards of Fuji and Gala cultivars. At harvest, appies produced in clusters of two, three or four fruits and isolated ones were evaluated for percentage of pest damage. A positive correlation between lhe number of fruits per cluster and percentage of appie leafroller damage was observed. The injury to fruits was higher during late season cultivar Fuji (harvested in April) than early season Gala (February). Fruits produced in isolated floral buds were significativelly less damaged by the pest than in cluster, indicating that is possible Io use apple thinning to reduce apple leafroller damage in commercial orchards.

Key words: Insecto, apple leafroller, fruit damage, cultural control.

\section{INTRODUÇÃO}

$\mathrm{O}$ raleio consiste na retirada dos frutos que se encontram em excesso nas plantas, visando evitar um desequilíbrio entre a produção e o crescimento vegetativo. Essa prática cultural é rotineiramente empregada pêlos pomicultores com o objetivo principal de aumentar e uniformizar o tamanho dos frutos e evitar a alternância de produção entre ciclos sucessivos (PEREIRAS $\boldsymbol{e t} \boldsymbol{a l}$, 1986).

A operação de raleio é realizada manualmente (após a frutificação efetiva) ou através de produtos químicos (carbaril, ácido naftaleno acético, entre outros), aplicados durante ou após a plena floração da macieira. Na maioria dos pomares comerciais do sul do Brasil, o raleio químico tem sido empregado seguido de um repasse manual, com o objetivo de melhorar a distribuição dos frutos nos cachos florais. Durante a operação manual, são retirados, além dos frutos em excesso, os malformados e/ou danificados por insetos e doenças. Após a floração, com o crescimento das maçãs nos ramos florais, é comum ocorrer a junção

\footnotetext{
${ }^{1}$ Engenheiro Agrônomo, Doutor, Pesquisador, Embrapa, Centro Nacional de Pesquisa de Uva e Vinho, CP 130, 95700-000, Bento Gonçalves - RS. E-mail: marcos@cnpuv.embrapa.br. Autor para correspondência.

${ }^{2}$ Engenheiro Agrônomo, Doutor, Professor do Departamento de Entomologia, ESALQ-USP.

${ }^{3}$ Engenheiro Agrônomo, Doutor, Pesquisador, Embrapa, Centro nacional de Pesquisa de Uva e Vinho, Estação Experimental de Vacaria Recebido para publicação em 14.05.99. Aprovado em 29.09.99
} 
das mesmas, formando cachopas que podem servir de abrigo para insetos como a lagarta-enroladeira Bonagota cranaodes (Meyrick, 1937) (Lepidoptera: Tortricidae), considerada uma das principais pragas da cultura na Região Sul do Brasil. Nessas situações, em hipótese, a presença de uma lagarta associada a frutos agrupados resultaria no dano de todas as maçãs presentes na cachopa, aumentando o número de frutos danificados no pomar.

Este trabalho foi realizado com o objetivo de avaliar o efeito do número de frutos por cacho floral sobre o dano causado pela lagarta-enroladeira, visando fornecer subsídios para o emprego do raleio como método cultural de controle do inseto na cultura da macieira.

\section{MATERIAL E MÉTODOS}

O trabalho foi realizado em pomares comerciais de macieira das cultivares Gala e Fuji, pertencentes à Agropecuária Schio, localizados em Vacaria, RS $\left(28^{\circ} 30^{\prime} \mathrm{S} / 50^{\circ} 54 \mathrm{~W}\right)$ durante a safra 1996/97. Os pomares foram implantados em 1988, sobre o porta-enxerto M 7, no espaçamento de 2,5 x $3,5 \mathrm{~m}$, sendo conduzidos de acordo com as técnicas de manejo da cultura. Nos dois pomares, o raleio foi realizado deixando-se, conforme o vigor dos ramos, frutos isolados ou de dois a quatro frutos por ramo floral.

Em 28/2 (Gala) e 18/4/1997 (Fuji), no momento da colheita, foi avaliado o dano causado pela lagarta-enroladeira em frutos mantidos isolados na planta e naqueles provenientes de cachos florais com duas, três e quatro maçãs. Para cada intensidade de raleio, foram avaliadas 10 sacolas (repetições) com capacidade média de 100 frutos cada, contandose o número dos danificados pelo inseto.

A porcentagem de frutos danificados (\%FD) foi correlacionada com o número de frutos por cacho floral (NFC) nas duas cultivares. Para a análise de variância, a \% FD foi transformada em arco seno $(\% 100)^{1 / 2}$, comparando-se as médias pelo teste de Duncan $(\mathrm{p}<0,05)$.

\section{RESULTADOS E DISCUSSÃO}

O dano causado pela lagarta-enroladeira variou significativamente entre as cultivares, independente do número de frutos por cacho floral (Tabela 1). Na cultivar Gala, o dano foi de 1,2\% (frutos isolados) a 3,4\% (quatro frutos por cacho floral), e na cultivar Fuji, a variação foi de $3,2 \%$ a $15,5 \%$, respectivamente. O menor dano verificado na Gala em relação à Fuji deve-se à colheita precoce (fevereiro) que reduz o risco de o fruto ficar exposto
Tabela 1 - Porcentagem média $( \pm \mathrm{EP})$ de frutos danificados por lagartas de Bonagota cranaodes nas cultivares Gala e Fuji em função do número de frutos por cacho floral. Vacaria, RS, 1997

\begin{tabular}{ccc}
\hline \multirow{2}{*}{$\begin{array}{c}\text { Número de frutos por } \\
\text { cacho floral }\end{array}$} & \multicolumn{2}{c}{$\%$ Frutos danificados } \\
\cline { 2 - 3 } & Gala & Fuji \\
\hline 1 & $1,2 \pm 0,16 \mathrm{aA}$ & $3,2 \pm 0,21 \mathrm{aB}$ \\
2 & $(985)^{*}$ & $(1025)$ \\
& $1,8 \pm 0,20 \mathrm{abA}$ & $5,1 \pm 0,37 \mathrm{abB}$ \\
3 & $(1010)$ & $(993)$ \\
& $2,8 \pm 0,12 \mathrm{bA}$ & $7,2 \pm 0,55 \mathrm{bB}$ \\
4 & $(1018)$ & $(998)$ \\
& $3,4 \pm 0,18 \mathrm{bA}$ & $15,3 \pm 1,12 \mathrm{cB}$ \\
& $(995)$ & $(1012)$ \\
\hline
\end{tabular}

Letras distintas maiúsculas na linha e minúsculas nas colunas diferem entre si pelo teste de Duncan ( $p<0,05$ ).

* número de frutos avaliados por tratamento.

ao ataque da praga. Nas duas cultivares, o dano causado pelo inseto aumentou significativamente a partir de dois frutos por cacho floral (Tabela 1).

Com base nesses resultados, comparandose um pomar manejado somente com um fruto por ramo floral com outro com dois frutos, no mesmo nível de infestação, haveria uma redução nos danos provocados pela praga em, aproximadamente, $67 \mathrm{e}$ $63 \%$ nas cultivares Gala e Fuji, respectivamente.

Foi obtida uma correlação positiva e significativa $(p<0,01)$ entre o número de frutos por cacho floral e a porcentagem de dano causado pela lagarta-enroladeira, tanto para a cultivar Gala ( $\mathrm{r}=$ $0,99)$ como para a Fuji $(r=0,91)$.

Quando vários frutos encontram-se agrupados num cacho floral, a presença de uma lagarta pode danificar todas as maçãs, não sendo necessário ao inseto sair do local em busca de alimentação ou abrigo. Com a prática do raleio, reduzindo-se o número de frutos por cacho floral, a lagarta precisa mover-se para causar danos em outras maçãs, o que reduz a quantidade de frutos danificados. A presença de frutos isolados na planta poderia deixar as lagartas mais expostas a ação dos inseticidas, bem como aos inimigos naturais.

Resultados semelhantes aos do presente trabalho foram observados por LAWSON et al. (1998) com a espécie Choristoneura rosaseana (Harris) (Lepidoptera: Tortricidae) na cultura da maçã nos EUA, indicando que a prática cultural pode ser utilizada para modificar a planta hospedeira e reduzir o dano provocado pelo inseto.

A redução do número de frutos por cacho floral resulta num aumento do tamanho $\mathrm{e}$ uniformidade das maçãs, pois eleva-se a relação 
entre o número de folhas e o número de frutos na planta (TISCÓRNIA, 1983). Comercialmente, entretanto, a produção de maçãs grandes nem sempre maximiza a produtividade e o retomo financeiro, visto que, dependendo da safra, o mercado comprador pode exigir frutos menores. Além disso, intensificar o raleio exige mais mão-deobra; por esses motivos, na análise da viabilidade da prática, além da redução nos danos causados pela lagarta-enroladeira, o tipo de fruto e a produtividade desejada também devem ser observados.

\section{REFERÊNCIAS BIBLIOGRÁFICAS}

LAWSON, D.S., REISSIG, W.H., AGNELLO, A.M. Effects of summer fruit prunning and hand fruit thinning on obliquebanded leafroller (Lepidoptera : Tortricidae) damage in New York state apple orchards. Journal of Agricultural Entomology, v.15, n.2, p.115-123, 1998.

PEREIRA, A.J., ELBERT, A., BRIGHENTI, E., et al. Raleio de frutos hl: EMPRESA CATARINENSE DE PESQUISA AGROPECUÁRIA. Manual da cultura da macieira. Florianópolis: Epagri, 1986. p.321-340.

TISCÓRNIA, J.R. Raleio em macieira. Pelotas : Embrapa, UEPAE, 1983. 18p. (Embrapa. UEPAE, Circular Técnica, 7).

Ciência Rural, v. 30, n. 4, 2000. 